\title{
Estudios
}

\section{Re-pensar el ex opere operato \\ Una consecuencia necesaria de la naturaleza popular de la liturgia}

\author{
Gonzalo Guzmán \\ FACUlTAD DE TEOLOGÍA \\ Pontificia Universidad Católica de Chile \\ pgguzmank@gmail.com
}

Resumen: La luz antropológica arrojada por Sacrosanctum Concilium y la eclesiología del pueblo de Dios en Lumen gentium llevaron a recuperar la dimensión popular de la sagrada liturgia y a comprenderla como lo que verdaderamente es: «una acción del y para el pueblo sacerdotal». Fundamento que no solo se expresa en una participación activa de la asamblea celebrante, sino también en una nueva aproximación teológica a la formulación del ex opere operato, en que la dimensión performativa de toda la celebración cobre verdadera importancia sacramental.

Palabras claves: performance, performativo, sacramentos, liturgia popular, corporeidad, ritualidad, ex opere operato.

Abstract: Sacrosanctum Concilium shed a light on the anthropologic aspect of liturgy and Lumen gentium offered an ecclesiology of the people of God. Both insights lead to the recovery of the popular dimension of sacred liturgy understood as it really is: "an act performed by and for the priestly people". This theology expresses itself not only in the active role of the celebrating assembly but also in a renewed understanding of the ex opere operato in which the performative dimension of the whole celebration in sacramental.

Keywords: performance, performativity, sacraments, popular liturgy, corporeality, rituality, ex opere operato. 


\section{INTRODUCCIÓN}

La teología sacramentaria clásica (la de la escolástica) fue recibida por el Magisterio entre los años 1215, con el Concilio de Constanza y 1563, con el Concilio de Trento. Ambos concilios establecieron el número septenario, aunque sin entrar en una definición del concepto sacramento, asumieron las categorías aristotélico-tomistas de materia-forma y abordaron otras preocupaciones, tales como el ministro y la intención ${ }^{1}$. En particular nos interesa la categoría ex opere operato recogida por Trento ${ }^{2}$ en función de la eficacia sacramental, es decir, el "que los sacramentos confieren la gracia por el hecho mismo de la acción realizada”. Pero ¿es posible hoy repensar el ex opere operato desde otra aproximación? La eclesiología del pueblo de Dios del Vaticano II y sus consecuencias antropológicas dispersas en Sacrosanctum Concilium y Lumen gentium así lo exigen.

"Por su naturaleza la liturgia es de hecho «popular» y no clerical, siendo -como enseña la etimología- una acción para el pueblo, pero también del pueblo [...] No debemos olvidar, por tanto, que es sobre todo la liturgia quien expresa la pietas de todo el pueblo de Dios”3.

Con estas palabras el Papa Francisco buscaba subrayar el hecho no clerical de la liturgia. Y sin embargo, rubrica la popularidad de esta como consecuencia del pueblo de Dios en cuanto pueblo crismado sacerdotal ${ }^{4}$. La categoría "popular" se desprende así totalmente de una visión socio-

1 Cf. SAnto Tomás de Aquino, De articulis fidei et Ecclesiae sacramenta. Opuscula teologica I (Maurini 1954) 141-154; Traducción al castellano: Santo Tomás DE AQuino, "Opúsculo sobre los artículos e la fe y los sacramentos de la Iglesia", en A. Osuna (dir), Opúsculos y cuestiones selectas. Edición Bilingüe IV, tr. L. López (BAC, Madrid 2007) 1153-1192; A. Fernández, Teología Dogmática II. Creación. Antropología. Eclesiología. Sacramentos. Escatología, (BAC, Madrid 2012) 414-425.

2 Cf. DH 1608.

3 Francisco, Discurso del santo padre francisco a los participantes en la 68 semana litúrgica nacional italiana, 24 agosto 2017, en: http://w2.vatican.va/content/francesco/es/ speeches/2017/august/documents/papa-francesco_20170824_settimana-liturgica-nazionale.html (descargado el 28 de mayo de 2018).

4 Cf. SC 7. 
cultural opuesta a una élite, siendo entendida como la derivación natural del ser pueblo 5 .

La popularidad de la liturgia es también consecuencia de la encarnación del Verbo, que siguiendo la pedagogía de la economía de salvación, asume la coyuntura histórico-cultural de un pueblo concreto, sujeto-objeto que crea y padece su propio ser popular con todas sus consecuencias diacrónicas. La liturgia, cuya piedra fundamental es dicho misterio cristológico, es popular porque su sujeto celebrante es el Cristo total, pueblo de Dios tomado de entre los pueblos e injertado en Cristo, encarnado en la historia ${ }^{6}$ para ejercer así su sacerdocio.

La asunción encarnatoria de la condición humana y de su concreto lenguaje espacio-temporal es la condición de posibilidad para que la sagrada liturgia pueda operar, "en ella los signos sensibles significan y, cada uno a su manera, realizan la santificación del hombre" ". Esto significa acoger las consecuencias celebrativas y comunicacionales de la opción cristológica por la dinámica popular. Francisco afirma:

“[...] nadie se salva solo, como individuo aislado, sino que Dios nos atrae tomando en cuenta la compleja trama de relaciones interpersonales que se establecen en la comunidad humana: Dios quiso entrar en una dinámica popular, en la dinámica de un pueblo"8.

Los redactores de Sacrosanctum Concilium, que conocían bien la teología escolástica, no recogieron sin embargo la terminología clásica de esta, sino que, por influjo del movimiento litúrgico, se abrieron a una aproximación basada en la celebración, entendiendo el culto como ejercicio del sacerdocio de Jesucristo por parte del pueblo de Dios mediante ritus et preces?. El liturgista italiano Alberto Dal Maso se preguntaba a finales de los años noventa: ¿es posible repensar el ex opere operato a partir de la

\footnotetext{
5 Cf. G. Guzmán, Lo popular' como lugar teológico de encuentro entre la liturgia y la piedad (CLV, Roma, 2016) 233-281.

6 Cf. SC 6-7.

7 SC 7.

8 GE 6.

9 Cf. SC 7. 48.
} 
antropología cultural $?^{10}$. Pareciera ser que el retorno de la liturgia a su lugar propio, es decir a la celebración, no ha sido lo suficientemente capaz de abrirse a sus consecuencias antropológicas (encarnatorias) como para reformular una nueva comprensión del ex opere operato sacramental.

Este verdadero giro copernicano obliga al liturgista a repensar el concepto ex opere operato desde una óptica antropológica en que la eficacia sacramental verdaderamente descanse en el lenguaje del pueblo asumido por la encarnación del Verbo y constituido sacerdote por la unción del Espíritu.

En este sentido, el lenguaje simbólico de la liturgia es expresión del ser popular del Christus totus celebrante. Por esto la ciencia litúrgica debe prestar atención a las propiedades de dicho lenguaje para abrirse desde ellas a nuevas comprensiones de la sacramentalidad. Para este desafío, un primero paso necesario es acoger la dimensión sacramental de la performatividad litúrgica en su "performance celebrativa".

El propósito del presente estudio es vencer la inercia de la sacramentaria escolástica para abrirse a la novedad del Vaticano II en la comprensión del ex opere operato.

\section{UNA CATEGORÍA CONTEMPORÁNEA: LA PERFORMANCE CELEBRATIVA}

Acoger el vocablo «performance» en toda su riqueza antropológica y aplicarlo a las celebraciones sacramentales ayudará a la tarea propuesta. Comprender la celebración del culto litúrgico en cuanto performance del pueblo sacerdotal obliga necesariamente a superar la comprensión anglosajona del concepto, normalmente aplicado a espectáculos de las más variadas artes o al desempeño de alguien o algo, para remontarse a la sentido latino del vocablo cuya raíz ya fue empleada por Tertuliano ${ }^{11}$ en el sentido de formar, crear o convertir plenamente. El prefijo «per-» latino indica cumplimiento o medio a través del cual se concluye una acción,

10 Cf. A. Dal Maso, L'efficacia dei sacramenti e la «performance rituale». Ripensare l'«ex opere operato» a partire dall'antropologia culturale (Edizioni Messaggero - Abbazia di Santa Giustina, Padova 1999).

11 Cf. Tertuliano, Apología 1, 10: "Sed non ideo, inquit, bonum, quia multos convertit. Quanti enim ad malum praeformantur, quanti transfugae in perversum, Quis negat?" 
en algunos casos cuando antecede un adjetivo busca agregar intensidad a dicho medio en cuanto su capacidad generadora. El verbo formo entre sus múltiples significados se traduce como: formar, crear, producir, prefigurar o simbolizar ${ }^{12}$. Aproximarse a la celebración litúrgica en cuanto performance es entender que en ella existe una potencialidad natural creativa, una capacidad humana generadora asumida por el misterio de la encarnación y pneumatizada por el misterio pascual. Desde esta perspectiva la sacramentalidad litúrgica abre sus horizontes al Misterio, según el deseo del Concilio Vaticano II, que, "procura que los cristianos no asistan a este misterio de fe como extraños y mudos espectadores, sino que comprendiéndolo bien a través de los ritos y oraciones, participen conscientes, piadosa y activamente en la acción sagrada" ${ }^{13}$. Significa abrirse a la riqueza de la acción de Dios en el lenguaje humano en sus dimensiones verbal y no verbal y, a su capacidad de ser expresión cierta, presencia real de la trascendencia en nuestros cuerpos, pensamientos, deseos, miradas, es decir, en nuestra humanidad ${ }^{14}$.

Es en esta línea de pensamiento que el profesor italiano Andrea Grillo entiende como necesaria una nueva comprensión de la experiencia celebrativa ritual:

“El surgimiento de categorías como 'juego' (Guardini), 'pensamiento total' (Casel), 'mediaciones' (Festugière) y 'conocimiento per connaturalitatem' (Vagaggini) indican una exigencia teorética, orientada a predisponer categorías más adecuadas, para comprender la experiencia ritual según una modalidad nueva respecto a la tradicional [...] una nueva noción de rito, que saliendo de la lógica del 'ritus servandus' y entrando en una de 'ritus celebrandus' se libere progresivamente de las forzadas concepciones rubricistas, ceremoniosas y devocionales $[\ldots]$ para acceder a aquella región de la 'acción comunitaria' inaccesible a las lógicas subjetivas y/o objetivas y visibles solamente a las lógicas intersubjetivas" ${ }^{\prime 15}$.

12 Cf. L. Rossi, (dir), Diq̧ionario della Lingua Latina (Hachette Livre \& Il capitello, Torino-Paris 2010).

13 SC 48.

14 Cf. SS 2.4.10; VD 53. 56.

15 A. Grillo, "Devotio moderna e devotio litúrgica. Il recupero del "sentiré emotivo" come condizione e stile della partecipazione alle azioni rituali”, en: L. Girardi, (ed.), Liturgia ed emozione (CLV Edizioni liturgiche, Roma 2015) 105-107. (La traducción al español es nuestra). 
Comprender la riqueza de la performance celebrativa significa abrirse a la complejidad de un entramado ritual popular capaz de evocar y hacer presente los misterios de Cristo hoy. Todo el lenguaje litúrgico, desde la convocación pneumatológica hasta la vivencia holística mistagógica, cuyo momento fuerte es el celebrativo por medio de signa sensibilia, tiene su rol fundamental para el hoy de la salvación actuado por la liturgia en un conjunto de relaciones intersubjetivas de estructura ritual. En otras palabras, preocuparse solo de asegurar la materia y la forma para la validez sacramental es una mezquindad para con el mismo pueblo de Dios, cuyo lenguaje cultural ha plasmado la riqueza del rito como generador de presencia. Por otro lado, desprender la liturgia de la ritualidad del proceso simbólico popular, capaz de hacer real y verdaderamente presente una realidad trascendente, para solo ser comprendida como rúbricas a cumplir con un neo-pelagianismo ${ }^{16}$ que brilla por su ostentación y perfección, es no entender la riqueza generativa del lenguaje humano y empañar la analogía de la encarnación a la cual está llamado el sujeto celebrante quedándose atrapado en una concepción legalista reducida.

La sociedad contemporánea de la modernidad tardía se empeña en iluminar las tinieblas de la supuesta ignorancia religiosa, como también de cualquier mito neo-positivista, para ser guía de una liberación o emancipación (de alguna manera anti-metafísica) del hombre como individuo casi aislado de su entorno. Para algunos autores, como los filósofos italianos Bruno Cescon y Gianni Vattimo, la razón aún siendo reconocidamente débi $1^{17}$ se enarbola como único parámetro de veracidad decantando en un neo-iluminismo ${ }^{18}$. Sin embargo, la liturgia con su lenguaje simbólico (performance) sigue dando respuestas concretas y eficaces a las preguntas límites a las que dicha razón técnica humana no logra responder, tales como el sentido de la vida, de la muerte, del dolor. En la liturgia y su performance, traspasada por la eficacia del Espíritu, el hombre abre una ventana comunicacional-experiencial hacia lo trascendente que le permite realmente cristificar su comprensión y vivencia de lo inmanente a partir del encuentro del chronos con el kairos en el aquí y ahora celebrativo.

16 Cf. GE 57-58.

17 Cf. G. VAтtimo, "Dialettica, differenza, pensiero debole", en: G. Vattimo - P.A. Rovatti, Il pensiero debole (Feltrinelli, Milano $\left.{ }^{7} 1990\right)$ 12-28.

18 Cf. B. CESCON, Liturgia grande sistema di comunicażione. Il potere comunicativo della liturgia nella modernità (CLV Edizioni liturgiche, Roma 2017) 57. 
Se debe aceptar que a la liturgia en un primer momento se accede por la experiencia; primero se celebra y luego entra el intelecto y la voluntad. La celebración litúrgica (signa sensibilia) es acción (ergon) que se expresa con gestos, con signos verbales y no verbales, con símbolos, con música, con movimiento corporal, con lugares y con espacios, con asamblea, con temporalidad, con épocas, en definitiva, con la popularidad del pueblo de Dios que celebra. En su performance celebrativa, la liturgia ofrece una visión total y universal de la existencia hablando experiencialmente a la razón y al corazón a través de la celebración misma y su intersubjetividad ritual ${ }^{19}$.

DE LA PERFORMANCE A LA PERFORMATIVIDAD. UNA LECTURA SACRAMENTAL DESDE LA ANTROPOLOGÍA

En los años cincuenta, el filósofo inglés del lenguaje John Langshaw Austin, en sus conferencias en la Universidad de Harvad publicadas póstumamente con el título How to do things with words, derivó del verbo perform la capacidad performativa del lenguaje, mediante el cual se crea, con un enunciado verbal inserto en una performance determinada, una nueva realidad no existente previamente. Ej: el compromiso matrimonial o un juramento $^{20}$. Análogamente se puede hablar de acciones performativas que gracias al lenguaje y sus diversos componentes son generadoras o poiéticas.

Esta perspectiva del lenguaje encontró acogida en el magisterio de Benedicto XVI y en la reciente carta apostólica Micericordia et misera ${ }^{21}$ de Francisco, ambos aplicándola directamente al mensaje cristiano y vinculándolo a una relación comunicacional intersubjetiva con hechos (performance) concretos transformantes generadores de vida nueva (metanoia). En efecto, afirma el Papa Benedicto:

"En nuestro lenguaje se diría: el mensaje cristiano no era sólo 'informativo', sino 'performativo'. Eso significa que el Evangelio no es solamente una comunicación de cosas que se pueden saber, sino una comunicación que comporta hechos y cambia la vida

19 Cf. B. Cescon, Liturgia grande sistema ..., 57-59. 84-85.

20 Cf. J. L. Austin, How to do things with words (Clarendon Press, Oxford 21975) 6-8.

21 Cf. MM 5. 
[...] ¿Es para nosotros 'performativa', un mensaje que plasma de modo nuevo la vida misma, o es ya sólo 'información' que, mientras tanto, hemos dejado arrinconada y nos parece superada por informaciones más recientes?"22.

Performatividad y performance se necesitan. Esta última es condición de posibilidad para la primera ${ }^{23}$. Retomando el ejemplo anterior, el "sí quiero" del consentimiento matrimonial (civil o religioso) adquiere su capacidad vinculante y generadora legal o canónica al interior de una determinada performance, de la misma manera que toda la ritualidad matrimonial sin el necesario consentimiento no es vinculante legalmente entre las partes. Una performance determinada puede ser decisiva en la capacidad performativa del actuar humano. En este sentido, Sacrosanctum Concilium, que señala el encargo de Cristo a la Iglesia "también a realizar la obra de salvación que proclamaban, mediante el sacrificio y los sacramentos" ${ }^{24}$, comprende que la liturgia es el lugar donde dicha performance celebrativa adquiere sentido de realidad y concretiza su capacidad sacramental de ser el hoy de los misterios de salvación. Al ser así, la celebración holística es la performance necesaria para la performatividad litúrgica. No da lo mismo cómo celebrar; el modo es tan importante como el fondo. Las rúbricas o normas contenidas en los rituales -como una suerte de guiones teatralesse transforman en vida nueva al ponerse en escena celebrativa: estas buscan asegurar la capacidad performativa de la celebración del pueblo de Dios. Es por ello que la celebración litúrgica no se entiende sino en el encuentro entre Dios y la persona concreta y su inter-relacionalidad ritual performativa al interior de la asamblea celebrante.

Desde una antropología de la performatividad del sujeto celebrante es ya el momento de vincular el ex opere operato con la necesaria performance celebrativa y en su densidad sacramental perfomativa de la que cada código del lenguaje formar parte .

22 SS 4.10.

23 Cf. R. TAgliaferri, "Ripetizione e pericolo rituale", en: C. Braga - C. M. Recta (dir.), Celebrare il mistero di Cristo. Manuale di liturgia a cura dell'Associazione Professori di Liturgia. Volume III La Celebrazione e i suoi linguaggi (CLV Edizioni liturgiche, Roma 2012) 115.

${ }^{24}$ SC 6. 
¿Cuáles son las condiciones para que una acción sea performativa? Principalmente los son de dos tipos: las institucionales y las sociales. Está inserta en un contexto comunitario, performance, donde uno de sus miembros goza de un carácter representativo ${ }^{25}$. En otras palabras es un acto socialpopular escénico, con una ritualidad establecida o asumida oficialmente por la comunidad. Esto lo hace ser autorreferencial y constitutivo de realidad dando espacio a una transformación de sus actores ${ }^{26}$.

\section{Performatividad e institución}

En la performatividad de la celebración litúrgica sin duda entran en juego elementos institucionales. En esta clave léase Sacrosanctum Concilium $\mathrm{N}^{\mathrm{o}} 22$ o su explicitación en el Código de Derecho Canónico:

"Las acciones litúrgicas no son acciones privadas, sino celebraciones de la misma Iglesia, que es 'sacramento de unidad', es decir, pueblo santo reunido y ordenado bajo la guía de los Obispos; por tanto, pertenecen a todo el cuerpo de la Iglesia, lo manifiestan y lo realizan; pero afectan a cada uno de sus miembros de manera distinta, según la diversidad de órdenes, funciones y participación actual [...] La ordenación de la sagrada liturgia depende exclusivamente de la autoridad de la Iglesia, que reside en la Sede Apostólica y, según las normas del derecho, en el Obispo diocesano"27.

La superación de la lectura legalista, que tanto trabajo le costó al movimiento litúrgico de los siglos pasados ${ }^{28}$, exige una re-comprensión de la estructura ritual litúrgica dada por las rúbricas. Si todo el pueblo de Dios es depositario del único sacerdocio de Jesucristo ¿cómo graduar la densidad sacramental o la capacidad performativa de estás? Un posible camino es abrirse a la necesaria apropiación institucional, por parte del pueblo sacerdotal, de ciertas estructuras rituales para que sean la performance

25 Cf. E. Fisher, Estética de lo performativo (Abada Editores, Madrid 2011) 49.

26 Cf. E. Fisher, Estética de lo performativo..., 51

27 CIC 837-838.

28 Cf. S. Marsili - D. Sartore, "Liturgia", en D. Sartore y otros (dir.), Liturgia (San Paolo, Cinisello Balsamo 2001) 1037-1054. 
necesaria que le asegure el grado performativo buscado. Las rúbricas, así entendidas y celebradas, pasan a ser el espacio temporal performativo que el pueblo de Dios ha dispuesto a lo largo de la historia (y que, por lo tanto, no es rígido ni fijo) para la anámnesis del misterio de Cristo y para la epiclesis pneumatológica que otorgan la eficacia sacramental.

El aparato de rúbricas debe ser oficializado y custodiado al interior del mismo pueblo de Dios, no para favorecer una celebración rubricista, sino para asegurar el necesario contexto performativo sacramental. Esto no es inocuo para la comprensión del ex opere operato, que se da al interior de la performance establecida por estas rúbricas. Sin embargo, ¿cuál debe ser la autoridad del pueblo de Dios que en su conjunto oficializa la ritualidad, dado que la celebración es siempre de una asamblea concreta con su carga popular de sujeto histórico, espacio temporal, determinado? Es volver a la conocida problemática de la necesaria autonomía, también celebrativa, de las Iglesias locales que parecieran encontrar dificultades en la apropiación del Rito Romano y su lenguaje simbólico performativo, que hoy en día resulta extraño para el pueblo de Dios en muchas regiones.

La cotidianeidad muestra que la praxis humana se comunica simbólicamente en la riqueza de la poiesis (creatividad) y la sagrada liturgia resulta ser un espacio performativo privilegiado para dicha dinámica. Más aún, por el hecho de que la poiesis litúrgica adquiere un plus trascendente gracias a la acción del Espíritu Santo que le otorga la eficacia pascual. Una liturgia así comprendida requiere una dedicación y una atención particular de cada uno de los componentes del lenguaje sacramental. Texto, música, artes visuales, teatro, espacio sagrado, se conjugan en la Iglesia orante para santificar al hombre y dar gloria a Dios. En otras palabras se trata de comprender las rúbricas y toda la performance a la luz del misterio que se celebra.

Por lo tanto, una liturgia popular no clericalista, como la deseada por el Papa Francisco en la cita que abre este artículo, significa evitar celebraciones litúrgicas amorfas o líquidas, también aquellas rígidas, para celebrar con conciencia performativa y con el mayor respeto a sus actores (Christus totus: "Cabeza y cuerpo») que le han otorgado a dichos signa sensibilia la oficialidad mistagógica necesaria para evocar y hacer presente los eventos de la historia de salvación. 


\section{LO SOCIAL DE LA PERFORMANCE Y SUS CONSECUENCIAS PERFORMATIVAS}

Diversos son los elementos que se entrelazan en toda acción performativa. Estos, posibles de definir como sociales, fundamentalmente son: el cuerpo, el movimiento y el tiempo y, el espacio ${ }^{29}$.

a. El estudio semiótico de la comunicación ha llevado a comprender el cuerpo humano como "la más plástica y dúctil de las materias significantes, la expresión biológica de la acción cultural $[\ldots]$ desde este punto de vista, la performance desarrolla verdaderos programas creativos individuales y colectivos" ${ }^{\prime 30}$, muchos de ellos configurados por la cultura, llegando a establecer secuencias de acciones y comportamientos (ritus) poiéticos, es decir, bajo ciertas condiciones, creadores $^{31}$. Este tipo de acciones son generadoras de identidad, constitutivas de realidad y de autorreferencialidad ${ }^{32}$.

Esta capacidad performativa corpórea es llevada a la máxima dignidad por la encarnación del Verbo en Jesucristo símbolo real de la presencia del Espíritu Santo en un cuerpo viviente. Es el asombroso escándalo del materialismo pneumático. No es indiferente a la teología lo concreto de Jesús de Nazaret: nace, camina, toca y se deja tocar. Tampoco lo es Jesús resucitado con su cuerpo glorioso (verificación de la encarnación). En Cristo corpóreo "signo-significante-presencia real" se identifican inaugurando la nueva ley de la sacramentalidad pascual otorgada al pueblo de Dios. Así por la analogía de la encarnación, el cristianismo es el anuncio de un evento corpóreo que atraviesa el devenir histórico con la capacidad de iluminar nuevas condiciones de conocimiento y participación a los eventos salvíficos ${ }^{33}$. En efecto se lee en 1Jn 1, 1-3:

29 Cf. J. Glusberg, El arte de la performance (Ediciones de arte gaglianone, Buenos Aires 1996) 39-56.

30 J. Glusberg, El arte de la performance..., 39-40.

31 Cf. J. Glusberg, El arte de la performance..., 40.

32 Cf. E. Fisher, Estética de lo performativo..., 55.

33 Cf. G. De Candia, "Hoc est corpus. Il contributo della teologia alla filosofia del corpo", en Rassegna di Teologia 54/2 (2013) 230-234. 
"Lo que existía desde el principio, lo que hemos oído, lo que hemos visto con nuestros ojos, lo que hemos contemplado y lo que hemos tocado con nuestras manos acerca de la Palabra de Vida, es lo que les anunciamos. Porque la Vida se hizo visible, y nosotros la vimos y somos testigos, y les anunciamos la Vida eterna, que existía junto al Padre y que se nos ha manifestado. Lo que hemos visto y oído, se lo anunciamos también a ustedes, para que vivan en comunión con nosotros. Y nuestra comunión es con el Padre y con su Hijo Jesucristo”.

Juan Pablo II, en un largo ciclo de catequesis de los días miércoles entre los años 1979 y 1984, profundizó en la denominada «teología del cuerpo». En febrero de 1980, reflexionando en torno al Génesis 1, en la bondad de la creación y en la dimensión corpórea de lo humano en cuanto a imagen de Dios, afirmaba:

"El sacramento, como signo visible, se constituye con el hombre, en cuanto 'cuerpo', mediante su 'visible' masculinidad y feminidad. En efecto, el cuerpo, y solo él, es capaz de hacer visible lo que es invisible: lo espiritual y lo divino. Ha sido creado para transferir a la realidad visible del mundo el misterio escondido desde la eternidad en Dios, y ser así su signo" 34 .

Toda acción ritual implica la corporeidad; el hombre se expresa y compromete mediante acciones rituales. Estas le permiten comunicarse y emitir una imagen de sí mismo. Toda la acción ritual exige una puesta en escena corpórea. Precisamente, el porte performativo del cuerpo humano capaz de hacer presente la realidad del misterio lo constituye en sacramento primordial. Por eso, "Dios miró todo lo que había hecho, y vio que era muy bueno" 35 , porque con el ser humano y su corporeidad aparece en el mundo la expresión más alta del don de Dios, como signos visibles de la economía del amor y la verdad ${ }^{36}$. Los sacramentos en la liturgia dan testimonio que lo más verdadero de la fe se realiza en lo concreto del cuerpo ${ }^{37}$.

34 Juan Pablo II, Audiencia general, 4, en http://w2.vatican.va/content/john-paul-ii/es/ audiences/1980/documents/hf_jp-ii_aud 19800220.html (descargado el 10 de julio de 2018).

35 Gn 1,31

36 Cf. Juan Pablo II, Audiencia general..., 5 .

37 Cf. D. Borobio, Cultura, fe, sacramento (Centre Pastoral Litúrgica, Barcelona 2002) 58. 
b. El movimiento y el tiempo son indispensables en toda performance, si bien el segundo claramente tiene relevancia sobre el primero ya que es posible una performance estática pero nunca una atemporal. La categoría temporal más que hacer referencia a la duración de la obra en cuestión está en relación al tiempo interno de la experiencia vivida por sus sujetos. Es un tiempo subjetivo diverso aún cuando se re-viva la misma performance. Esto hace que las repeticiones jamás sean idénticas dependiendo de las condiciones psicológicas de todos los actores. Aun más, no se debe olvidar que toda performance es comunicativa. Si el tiempo incide en el cambio subjetivo de sus actores (comunicadores y receptores) la performance variará ${ }^{38}$.

El movimiento, siempre sujeto al tiempo y al cuerpo, se expresa en distintos códigos comunicativos que permiten la performatividad gracias a la dinámica del simbolismo. Existe el código odológico, referente a los movimientos al interior de un espacio; el código kinésico, abarcando todo aquello relativo a los movimientos corporales, en que no es solo el hecho de estar en una determinada postura, sino el ergon de sentarse, de alzarse, de inclinarse o de arrodillarse; el código táctil con su gama de gestos basados en palpar, recibir y traspasar información por medio del tacto ${ }^{39}$. En el movimiento ritual, la acción (en sus diversos códigos) y las palabras no son solo una consecuencia natural, sino un constructo cultural que asumen una capacidad creadora ${ }^{40}$.

Movimiento y tiempo en la celebración litúrgica jamás pueden ser desligados de la condición popular de la asamblea celebrante. En efecto, el ser popular abarca la comunicación no verbal mediante signa sensibilia. La incidencia del movimiento de la ritualidad en el ex opere operato se desprende de la comprensión clásica de este, "por el hecho mismo de que

\footnotetext{
38 Cf. J. Glusberg, El arte de la performance..., 55.

39 Cf. G. Guzmán, 'Lo popular' como lugar teológico..., 324.

40 Cf. G. Bonaccorso, "Il contesto rituale della parola", en A.N. Terrin (dir.), La natura del rito. Tradizione e rinnovamento (Edizioni Messaggero - Abbazia di Santa Giustina, Padova 2010) 287.
} 
la acción es realizada" ${ }^{41}$. Yendo más allá, ser popular incluye temporalidad. Toda asamblea es pueblo, y, en cuanto tal, es sujeto histórico capaz de autodeterminarse en un proceso natural de toma de conciencia frente a los acontecimientos espacio temporales que padece. El ser popular de la liturgia no le permite ser anacrónica, más bien le exige ser diacrónica, prestando atención a los tiempos chronos y kairos de los miembros del pueblo sacerdotal.

Si la performatividad tiene entre sus componentes fundamentales la temporalidad, el ex opere operato comprendido a partir de performatividad sacramental no puede ser separado del tiempo y de las consecuencias que este trae para la asamblea celebrante. Concebirlo asépticamente, descontaminado del hodie litúrgico en su bi-demensionalidad del hoy cronológico y del hoy salvífico, cuyo misterio se está haciendo presente, pareciera alejarse del camino de la encarnación y de su analogía sacramental. Una lectura de este tipo no quiere decir que la eficacia de la justificación en los sacramentos esté ligada a la dignidad del ministro o a la mera subjetividad del sujeto celebrante, sino de repensar la sacramentalidad y su eficacia salvífica a partir del Verbo encarnado que lejos de actuar "mágicamente" lo hizo en la concreción de lo real de la corporeidad, donde la potencialidad sacramental performativa está traspasada por el tiempo. El rito puede ser entendido como una performance transformante solo cuando está íntimamente unido a los procesos generados a través del tiempo en el sujeto celebrante, es decir su cultura ${ }^{42}$. ¿Es performativo para el sujeto de la modernidad tardía un rito que culturalmente, o sea popularmente, es representativo de un pueblo (asamblea) de hace dos mil años? ¿Para una comunidad americana, africana o asiática es performativa una ritualidad cuyo humus cultural es europeo? Abrirse verdaderamente a una liturgia popular y no clerical significa repensar la eficacia sacramental ex opere operato corriendo el riesgo de asumir lo humano en serio, Jesucristo demostró que ese es el camino.

c. La performance tiene lugar en y por la realización escénica que acontece en un espacio determinado que, yendo más allá de los volúmenes geométricos que este pueda contener o ocupar es un espacio performativo,

\footnotetext{
41 DH 1608; Cf. CEC 1128.

42 Cf. G. Bonaccorso, Rito (Edizioni Messaggero, Padova 2015) 60
} 
brinda diversas posibilidades a movimientos y percepciones dando lugar a la relación personal de los distintos actores que en él interactúan de un modo muchas veces impredecible. En este espacio también debe ser considerada la atmósfera que el palco escénico, con sus elementos concretos, pueda irradiar. Si bien estas (atmósferas) son a-tópicas, porque superan y van más allá del lugar físico, son de vital importancia para la capacidad performativa. Por lo general, son el primer impacto que reciben los sujetos involucrados. La atmósfera, producto de la conjunción de múltiples elementos materiales e inmateriales, tiene la capacidad de teñir, de traspasar, el tejido ritual en vistas a una determinada poiesis. La atmósfera no pertenece a lo objetivo ni a lo subjetivo, sino que brota de las propiedades de las cosas materiales involucradas en la performance y de la percepción de los individuos que a ella participan. De algún modo la atmósfera es el espacio de presencia performativa ubicada entre la objetividad del espacio geométrico y la subjetividad de la persona. Esta, comprendida así liminalmente, es capaz de transformar lo geométrico en poiético $^{43}$.

En el culto cristiano el espacio celebrativo y sus lugares son múltiples. Estos, traspasados y diferenciados por las épocas y culturas, conservan algunos elementos constitutivos: acoger al sujeto celebrante, es decir a la asamblea y facilitar la celebración de los misterios salvíficos. La atmósfera por y en ellos producida debe, por su dignidad y belleza, ser signo y símbolo de las realidades celestes favoreciendo el carácter performativo de las celebraciones litúrgicas ${ }^{44}$.

Respecto al sujeto celebrante, el Vaticano II puso todo su acento en la participación activa, consciente y fructuosa de quienes lo conforman ${ }^{45}$. La liturgia debe ser reflejo de una eclesiología que toma conciencia de ser pueblo sacerdotal donde las acciones litúrgicas jamás son privadas, sino de todo el cuerpo de la Iglesia ${ }^{46}$. Es este el depositario del único y eterno sacerdocio de su Cabeza; por ello la llamada a los obispos a procurar

\footnotetext{
43 Cf. E. Fisher, Estética de lo performativo..., 221-244.

44 Cf. IGMR 288; P. JouneL, "Luoghi della celebrazione", en D. Sartore y otros (dir.), Liturgia (San Paolo, Cinisello Balsamo 2001) 1110.

45 Cf. SC 11. 14-19. 21. 27. 30. 41. 48. 50.79.

46 Cf. SC 26.
} 
con diligencia que el espacio litúrgico sea apto para la celebración y participación activa de los fieles poniendo de manifiesto el ser asamblea congregada ${ }^{47}$.

La asamblea congregada en oración y alabanza es presencia de $\mathrm{Cristo}^{48}$ cuyo ejercicio sacerdotal encuentra su máxima concretización sacramental en la liturgia. Si bien la presencia física de esta no es requisito para la validez de las acciones litúrgicas, ella constituye el clima ideal para su celebración. Las acciones litúrgicas se orientan a la asamblea y la asamblea ejercita su acción más noble como sacramento de unidad en las acciones litúrgicas ${ }^{49}$. De este modo, todo, tanto el espacio físico y sus elementos geométricos, como la asamblea celebrante, son la atmósfera performativa propia de la liturgia. Separarlas es desconocer la génesis de la celebración cristiana, privar al pueblo de Dios del derecho y deber bautismal de ejercer su sacerdocio en el culto y dañar la capacidad performativa de la sagrada liturgia. La atmósfera sacerdotal del pueblo de Dios orante favorece la poiesis sacramental por su íntima vinculación a Cristo sumo y eterno sacerdote. La asamblea es el verdadero templo viviente ${ }^{50}$, edificado por Dios mismo para la celebración.

Toda la disposición de los lugares al interior del espacio litúrgico deben estar en función de la celebración sacerdotal de la asamblea y del misterio celebrado. Así, por ejemplo, para la synaxis eucarística, presbiterio, altar, ambón, sede y todo su ornato deben potenciar mistagógicamente la participación activa de todos los congregados ${ }^{51}$. En estos no debe primar jamás un devocionalismo particular de quien preside, sino ser casa de oración comunitaria en la que se celebra la cumbre de la sacramentalidad. El ejercicio litúrgico de comparar el ordo missae del misal tridentino con el del Vaticano II permite inmediatamente darse cuenta de que el primero contenía la misa celebrada por un sacerdote junto a un ministro acompañante, mientras que el segundo refleja la celebración del pueblo

\footnotetext{
47 Cf. SC 124; IGMR 294.

48 Cf. Mt 18, 19-20; SC 7.

49 Cf. A. Cuva, "Assemblea", en D. Sartore y otros (dir.), Liturgia (San Paolo, Cinisello Balsamo 2001) 160.

50 Cf. Ef 2, 22; 1Cor 3, 17; 1Pe 2, 5.

51 Cf. IGMR 295-318.
} 
de Dios presidida por un presbítero ${ }^{52}$. En efecto, los padres del Vaticano II afirman: "La principal manifestación de la Iglesia se realiza en la participación plena y activa de todo el pueblo santo de Dios en las mismas celebraciones litúrgicas, particularmente en la misma Eucaristía, en una misma oración, junto al único altar donde preside el Obispo, rodeado de su presbiterio y ministros" 53 .

El segundo elemento constitutivo del espacio celebrativo cristiano son precisamente los misterios salvíficos que todo el lenguaje simbólico litúrgico, mediante ritus et preces, hace presente en la celebración. En este sentido, la atmósfera performativa de la liturgia debe procurar siempre evocar dichos misterios. Errar en ello no es inocuo. Esto conlleva el no descuidar el rito y todo lo que este implica, como tampoco no ahogar el contenido teológico por el rito mismo o su atmósfera. Las celebraciones litúrgicas son el momento existencial donde el simbolismo natural viene transfigurado y re-significado por el evento cristiano ${ }^{54}$. Toda la atmósfera y la ritualidad en ella celebrada es el equilibrio entre la acción humana y el don recibido ${ }^{55}$. La sagrada liturgia no es solo algo instituido por Cristo, sino la continuación ritual de sus misterios; es el espacio celebrativo donde hoy acontece la salvación ${ }^{56}$.

Si la atmósfera es espacio de presencia performativa donde lo geométrico llega a ser poiético, en la celebración litúrgica los volúmenes geométricos que favorecen la participación de la asamblea junto a esta última son atmósfera performativa mistagógica en la cual la ritualidad anamnética del pueblo de Dios, traspasada por el Espíritu, es poiesis epiclética del misterio pascual.

52 Cf. P. Jounel, “Luoghi della celebrazione...”, 1121.

53 SC 41.

54 Cf. R. TAgliaferri, "Lo spazio architettonico nella performance liturgica”, en: C. Braga - C. M. Recta (dir.), Celebrare il mistero di Cristo. Manuale di liturgia a cura dell'Associazione Professori di Liturgia. Volume III La Celebrazione e i suoi linguaggi (CLV Edizioni liturgiche, Roma 2012) 346-347.

55 Cf. L. Della Pietra, Rituum forma. La teologia dei sacramenti alla prova della forma rituale (Edizioni Messaggero - Abbazia di Santa Giustina, Padova 2012) 326-329. 333.

56 Cf. B. Neunheuser, "Mistero", en D. Sartore y otros (dir.), Liturgia (San Paolo, Cinisello Balsamo 2001) 1230. 
498 |Gonzalo Guzmán

\section{LA FORMA RITUAL POPULAR COMO “MEDIACIÓN" DE LA GRACIA}

La osadía de la historia de la salvación y del misterio de la encarnación no solo significa que las culturas son el escenario en el cual se da el evento salvífico entre Dios y su pueblo, sino que Dios se ha ligado a condiciones sociales, culturales, asumiendo un pueblo y su popularidad ${ }^{57}$. En Jesús, Dios ha tomado consistencia humana, en Él está la mayor unidad y la mayor diferencia entre lo humano y lo divino. Esto significa que los cristianos son llamados a vivir su salvación trascendente, en el mundo, y no alejándose de $\operatorname{este}^{58}$. Por analogía a la encarnación esto lleva aceptar que la forma ritual y su espacio más que un medio son "medición" de la gracia, es decir, no una expresión externa (signo) de la trascendencia sino lugar donde se opera la salvación. De esta forma los elementos rituales asumidos de la popularidad del pueblo de Dios lejos de ser una barrera entre Dios y los hombres, son la medicación necesaria donde el símbolo actúa, comunica y efectúa el encuentro intersubjetivo divino-humano. El cuerpo viviente, su movimiento en el tiempo, el espacio (atmósfera) y la institucionalidad necesaria interactúan con lo inmanente y trascendente para que así el hombre pueda entrar en comunión con la realidad salvífica en la experiencia simbólica ritual. El creyente cristiano no está llamado a vivir en una ilusión de la presencia inmediata de Dios, sino a acoger una fe que no teme al cuerpo, ni al tiempo, ni al espacio, como tampoco a sus instituciones. "Esta paradoja [...] expresa el desafío quizás más grande de la fe cristiana: es decir que no nos podemos elevar a la altura del Absoluto divino si no nos dejamos involucrar en (por) las realidades más humanas de este mundo" 59 . La comunicación con Dios viene mediada estrechamente por dicha realidades ${ }^{60}$. En esto consiste la mediación sacramental de la antropología litúrgica del Vaticano $\mathrm{II}^{61}$.

57 Cf. VL 9-10.

58 Cf. L.M. Chauvet, Della mediaz̧ione. Quattro studi de teologia sacramentaria fondamentale (Citadella Editrice - Pontificio Ateneo Sant'Anselmo, Assisi-Roma 2006) 52-53.

59 L.M. Chauvet, Della mediażione..., 48-49. (Original en francés e italiano. La traducción es nuestra).

60 Cf. L.M. Chauvet, Della mediazione..., 48-49.

${ }^{61}$ Cf. L. Della Pietra, Rituum forma..., 326. 
Repensar la teología del ex opere operato desde la antropología litúrgica es asumir la dignidad sacramental de lo creado, en particular del ser humano y su corporeidad espacio-temporal como medición de la gracia. No cabe duda de que los sacramentos actúan en virtud de la obra de Cristo y no por la justicia del hombre que celebra ${ }^{62}$, mas tampoco cabe duda que dicha obra salvífica es en lo humano.

Desde una teología litúrgico-pastoral, esta aproximación al ex opere operato significa el desafío de comprender las celebraciones litúrgicas insertas en la dinámica cultural del pueblo de Dios y de los pueblos que este congrega. Lo opuesto resulta ser contradictorio a la liturgia misma. Exigir al sujeto celebrante una ritualidad performativa ajena a su corporalidad y dinámica espacio-temporal concreta (cultural), es forzar el lenguaje simbólico hacia una pérdida de realidad, obligando al teólogo a elaborar reflexiones sobre la eficacia sacramental a las que lo humano es ajeno. La liturgia no es ex-nibilo, por el contrario, el lenguaje simbólico es un acontecimiento que exige conocer la evolución cultural de los pueblos y del pueblo de Dios $^{63}$.

Como Iglesia Católica latina, somos herederos de una doble fijación del Rito Romano; la de Carlo Magno y la tridentina. Si bien el Concilio Vaticano II no desea imponer una rígida uniformidad y desea promover los genios locales ${ }^{64}$, aún hoy existe un temor a nuevos ritos más allá del Romano, del Ambrosiano y del Hispánico-Mozarábico. Mientras exista una rigidez ritual, todo el esfuerzo será por inculturar el Romano a las culturas locales, lo cual es un paso positivo y muy deseado. Pero la lógica encarnatoria va más allá: no consiste en adaptar o inculturar, sino en que el rito mismo sea propio de la cultura para una mediación eficaz de la gracia. Este es el desafío al momento de repensar la teología del ex opere operato a partir de la naturaleza popular de la liturgia. La participación

\footnotetext{
${ }^{62}$ Cf. CEC 1128.

${ }^{63}$ Cf. G. Guzmán, "San Cristóbal de Las Casas - Una experiencia de inculturación", en Medellin 42/169 (2017) 717.

${ }^{64}$ Cf. SC 37.
} 
activa y fructuosa de la asamblea es más profunda que su sola performance celebrativa; es reconocer la capacidad performativa de esta, fundada en su ser pueblo, en que la praxis celebrativa es poiesis sacramental. Si el rito es expresión sacramental de una iglesia, ¿es posible que este rito sea extraño para una gran parte del mundo occidental?

\section{CONCLUSIÓN}

\section{RECUPERAR LA MISTAgOGÍA CELEBRATIVA DEL ARS CELEBRANDI}

Si la celebración litúrgica es comprendida con esta densidad performativa de la sacramentalidad, se exige, por parte del sujeto celebrante, es decir, de la asamblea, tomar conciencia de la necesidad de empeñarse en calibrar debidamente la relación entre el rito y el evento salvífico (misterio) actuante. Desde esta antropología litúrgica se debe evitar toda posibilidad de un rito aguado o desnaturalizado, ya sea por su desconexión con los misterios de Cristo o por desafección hacia la ritualidad simbólica. Para que un símbolo verdaderamente produzca el encuentro poiético, debe aparecer en toda su verdad sin reducciones intelectuales, es decir, acogiendo toda su densidad en cuanto vía (mediación) sacramental señalada por la encarnación del Verbo. Entender la liturgia como acción popular es adentrarse a la sacramentalidad desde la sencillez de la kénosis, desde lo corpóreo, para llegar a la experiencia de lo trascedente ${ }^{65}$.

Toda la celebración es, en su lenguaje anamnético, una red de relaciones intersubjetivas populares instituidas por Cristo y asumidas eclesialmente. Estas constituyen la mediación necesaria para la acción epiclética del Espíritu. Desde esta perspectiva, el ex opere operato exige cuidar de toda la celebración en cada uno de sus códigos de encuentro y comunicación. Quien preside y cada uno de los ministros, deben recordar que cada parte en el todo favorece dicha red simbólica - sacramental ${ }^{66}$. El arte de celebrar, por tanto, está lejos de ser un perfeccionismo obsesivo por la rúbrica o una excesiva atención por la suntuosidad o una desafección por la ritualidad establecida, para dar paso a una creatividad pastoral desmedida, sino que es la capacidad del sujeto celebrante de poner en perfecta armonía

65 Cf. L. Della Pietra, Rituum forma..., 331-332.

${ }^{6}$ Cf. G. Guzmán, "San Cristóbal de Las Casas...”, 716-717. 
performativa esta red, siendo consciente de que en ella radica el ex opere operato sacramental. Para ello es imprescindible conocer en profundidad los misterios histórico-salvíficos desplegados celebrativamente a lo largo del año litúrgico, la ritualidad del pueblo de Dios que navega en la historia sin rigideces y la teología de las celebraciones litúrgicas, que es la lex credendi imprescindible del culto en espíritu y en verdad. Una verdadera liturgia popular exige, a quien celebra, ser verdadero y humilde mistagogo, ser hombre del misterio, prestando reverente atención a los más mínimos detalles como lugares de gracia y, a quien preside, ser ministro servidor del pueblo sacerdotal que evocando los misterios divinos es santificado rindiendo el culto debido a Dios. 


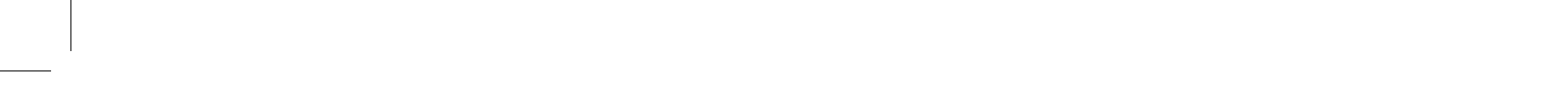

